\section{An interactive FORTRAN IV program for calculating aspects of power in correlational research}

\section{WILLIAM P. DUNLAP and EDWARD R. KEMERY Tulane University, New Orleans, Louisiana}

In designing correlational studies, the issue of statistical power is extremely important. Power is the probability that a correlation, if it exists, will be significantly different from zero in a given experiment. The importance of determining power in experimental planning was highlighted by Schmidt, Hunter, and Urry (1976), who reported that statistical power in many correlational investigations was much lower than that required for meaningful research. Tversky and Kahneman (1971) pointed out that researchers assume greater power than small samples actually provide. Schmidt et al. (1976) reported a general agreement that sample sizes from 30 to 50 were adequate for criterion-related validity studies. Moreover, the median sample size for all validity studies (both published and unpublished) was estimated to be between 40 and 70 (cf. Guion, 1965; Lent, Aurbach, \& Levin, 1971). Schmidt et al. (1976) noted that the common intuitive overestimation of power with small samples has major implications for the valid interpretation of correlational results. Because the power of a design is a complex function of sample size, alpha level, population variance, and actual effect size, few researchers bother to compute power. Thus, many correlational studies, because of small sample sizes, may lack sufficient statistical power to reach valid conclusions about the relationships that may or may not exist between variables.

Schmidt et al. (1976) outlined a procedure for estimating the level of statistical power in correlational designs. This approach takes into account the possibility that the variables may be collected from a limited sample (i.e., a restriction of range), and that the instruments employed in the investigation may provide unreliable measures of the constructs under investigation. When this approach was applied to studies in which sample sizes were in the "typical" range, statistical power was found to be disturbingly low. Researchers often were misled by the results of their experiments.

Other reasons why investigators have neglected the issue of power are the inaccessibility of the necessary formulas and appropriate statistical tables, and the level of statistical sophistication required to calculate power (Cohen, 1977). The program listed here provides researchers and practitioners with estimates of statistical power, without their having to track down tables and formulas from the

W. P. Dunlap's mailing address is: Department of Psychology, Tulane University, New Orleans, LA 70118. statistical literature, and without their having to perform complex calculations or table interpolations.

The program is written in the same general manner as two previous programs, one to compute power for designs to be analyzed by analysis of variance (Dunlap, 1981), and one to determine power for frequency data where the usual method of analysis is chi-square (Dunlap, 1982).

The Program. The program is designed to operate interactively in planning or assessing correlational research. It first requests the alpha level (two-tailed). Two options are employed only if the user is familiar with the issues and complexities of corrections for range restriction and unreliability, and has worked through some general treatment such as that of Schmidt et al. (1976). The program asks whether the user would like to correct for restriction of range. If the reply is "yes,"' the user is asked to enter the population standard deviation (SD), followed by the SD of the sample. Generally, the sample SD will be smaller than the full population SD, if the sample has been preselected on some basis that relates to the predictor, or if there is self-selection or other sample mortality related to the predictor or criterion. Usually, if the predictor is a standardized instrument, then population norms will provide the population SD, and the sample SD can be computed directly from the data. Next, the program asks whether the user wishes to correct for unreliability. If the response is "yes," the user is asked to enter reliability estimates for the criterion and the predictor (a reliability of one may be entered where no correction is required). At this point, the user is given the choice of computing either power, sample size, or the detectable correlation. In order to calculate any one of these three aspects of power, values must be entered for the other two. For example, to compute sample size, the program first requests a value for the population correlation. The program then responds with the correction for range restriction and the correction for less than perfect reliability, if these items were selected earlier. Next, the program asks the user to enter the desired power, and responds with the sample size that would produce power closest to that requested. The other options are executed in a similar interactive manner, allowing the user to review the various aspects of power under whatever variety of conditions are entered.

Several algorithms were tested for both efficiency and accuracy in computing the power associated with the test of significance for a correlation coefficient, using Monte Carlo simulation as a guidepost. Both the procedure used by Cohen (1977) and that used by Schmidt et al. (1976) were found to be reasonably accurate; the latter was chosen because it is computationally simpler. Power is calculated by first solving:

$$
\mathrm{Z}_{\mathrm{P}}=\mathrm{Z}_{\mathrm{A}}-\mathrm{Z}_{\mathrm{R}} * \operatorname{SQRT}(\mathrm{N}-3) ;
$$


where $\mathrm{Z}_{\mathrm{A}}$ is the normal curve critical value at alpha (1.96 for alpha $=.05$ ); $Z_{R}$ is the Fisher $z$ transformation of the correlation coefficient; $N$ is the sample size; and $Z_{P}$ is a normal curve value from which power may be derived. Power is the area above $Z_{P}$ on the normal curve, and is computed in the present program by ZPRB, a function described by Dunlap and Duffy (1975).

To compute sample size, $Z_{P}$ is first found by computing a one-tailed critical value from the normal curve above which the area equals the desired power. Then, the following expression is solved for the necessary sample size:

$$
\mathbf{N}=\left[\left(\mathbf{Z}_{\mathrm{A}}-\mathrm{Z}_{\mathrm{P}}\right) / \mathrm{Z}_{\mathrm{R}}\right]^{2}+3
$$

where the terms have the same definition as in Equation 1 above.

The detectable correlation is found by first solving:

$$
\mathrm{Z}_{R}=\left(\mathrm{Z}_{A}-\mathrm{Z}_{P}\right) / \mathrm{SQRT}(\mathrm{N}-3) ;
$$

then computing the back solution of the Fisher $\mathrm{z}$ transformation on $Z_{R}$ to obtain $r$, the detectable correlation coefficient. The program computes the correlation that would be detectable under the previously specified conditions for both range restriction and less than perfect reliability; therefore, after displaying the detectable sample correlation, the program computes the population correlation that might be obtained under conditions of no range restriction and perfect reliability. The user should be aware that these latter values may exceed one, indicating that the current conditions are unrealistic for valid correlational research.

Accuracy. The accuracy of several algorithms for computing correlational power was compared to Monte Carlo estimates of power. These estimates were obtained by generating 10,000 samples of data with each specified population correlation and sample size, then counting the number of significant outcomes via the F test and Fisher's z. These results are reported in Table 1 along with the power estimates using the program described here. The power estimates of our program were close to those estimated by simulation, the greatest discrepancies occurring at intermediate power values. Where discrepancies exist, the computed power values underestimate the empirical estimates, and tend to be conservative. Furthermore, the computed values generated by this program agree with values reported in Schmidt et al. (1976). Therefore, either values from Table 1 or those of Schmidt et al. (1976) can be used to verify that the program is running correctly on a new system.

Requirements. The program is written in single precision FORTRAN IV and runs on a DEC-2060 computer. The program is designed to run interactively using a CRT terminal for input and output. Although efforts were made to avoid using DEC-specific FORTRAN statements, a few nonstandard features were included to make the program run conveniently on the DEC system. The user probably will have to modify the statements assigning logical units
Table 1

Comparison of Power to Detect Significant Correlation with Sample Sizes of $5,10,20$, and 30, and Correlations of .1 to .9, Between Monte Carlo Estimates of Power by the $F$ test $[E(F)]$, the Fisher's $Z$ test $[E(Z)]$, and Estimates by the Present Program (P)

\begin{tabular}{cccccc}
\hline & & \multicolumn{4}{c}{ Sample Size } \\
\cline { 3 - 6 } Correlation & Estimate & 5 & 10 & 20 & 30 \\
\hline \multirow{2}{*}{.1} & $\mathrm{E}(\mathrm{F})$ & .0515 & .0590 & .0700 & .0852 \\
& $\mathrm{E}(\mathrm{Z})$ & .0319 & .0482 & .0608 & .0800 \\
& $\mathrm{P}$ & .0345 & .0451 & .0610 & .0751 \\
.3 & $\mathrm{E}(\mathrm{F})$ & .0763 & .1334 & .2597 & .3711 \\
& $\mathrm{E}(\mathrm{Z})$ & .0643 & .1334 & .2404 & .3722 \\
& $\mathrm{P}$ & .0640 & .1269 & .2471 & .3626 \\
.5 & $\mathrm{E}(\mathrm{F})$ & .1321 & .3214 & .6466 & .8216 \\
& $\mathrm{E}(\mathrm{Z})$ & .1233 & .3240 & .6495 & .8229 \\
& $\mathrm{P}$ & .1184 & .3062 & .6198 & .8144 \\
.7 & $\mathrm{E}(\mathrm{F})$ & .2637 & .6771 & .9560 & .9958 \\
& $\mathrm{E}(\mathrm{Z})$ & .2536 & .6810 & .9564 & .9958 \\
& $\mathrm{P}$ & .2317 & .6311 & .9469 & .9945 \\
.9 & $\mathrm{E}(\mathrm{F})$ & .6746 & .9812 & .9999 & 1.0000 \\
& $\mathrm{E}(\mathrm{Z})$ & .6638 & .9819 & .9999 & 1.0000 \\
& $\mathrm{P}$ & .5486 & .9735 & .9999 & 1.0000 \\
& & & & &
\end{tabular}

if the program is to run on computers other than DEC. Also the symbol " $\$$ " in READ statements causes the cursor to remain at the end of a line on the CRT, a feature which is cosmetic but unnecessary. Finally, the asterisk in place of a FORMAT statement number allows free format input on the DEC.

Availabilty. A listing of the program may be obtained at no charge from W. P. Dunlap. We also have compiled the program successfully on the IBM PC. If the IBM PC version is requested, a double-sided, double density, softsectored, $5 \frac{1 / 4}{1}$ in. floppy disk should accompany the request.

\section{REFERENCES}

COHEN, J. (1977). Statistical power analysis for the behavioral sciences. New York: Academic Press.

DUNLAP, W. P. (1981). An interactive FORTRAN IV program for calculating power, sample size, or detectable differences in means. $B e$ havioral Research Methods \& Instrumentation, 7, 757-759.

DUNLAP, W. P. (1982). An interactive FORTRAN IV program for calculating aspects of power with dichotomous data. Behavior Research Methods \& Instrumentation, 14, 422-424.

DUNLAP, W. P., \&UFFY, J. A. (1975). FORTRAN IV functions for calculating exact probabilities associated with $\mathrm{z}$, chi-square, $\mathrm{t}$, and F values. Behavior Research Methods \& Instrumentation, 7, 59-60. Guion, R. M. (1965). Personnel testing. New York: McGraw-Hill. Lent, R. H., Aurbach, H. A., \&evin, L. S. (1971). Predictors, criteria, and significant results. Personnel Psychology, 24, 519-533.

SCHMidT, F. L., HunTer, J. E., URRY, V. W. (1976). Statistical power in criterion-related validation studies. Journal of Applied Psychology, $61,473-485$.

TVERSKY, A., \& KAHNEMAN, D. (1971). Belief in the law of small numbers. Psychological Bulletin, 76, 105-110.

\section{APPENDIX}

DIHENS ION XB(100) OPEN (UNIT $=5$, DEVICE E'ITY') OPEN (UAIT $=6$, DE VICE.'TTY') WRITE $(6,1)$ Fonat ( $)$ 
2 FORMAT' THIS PRUGRAM WILL HELP YOU DESIOH CORKELATIOHAL', I RESEARCH WICH HESPECT TO PUWLA. DN ADDITION TO COMPUTINO Y, 3 I AND LESS THAN PEREECI RELIABILITY IN YOUR VAHIABLES. ')

WRITE $(6,1)$

$S D P=1.0$

$S D S=1.0$

$R C+1.0$

RPI1.0
WRITE $(6,4)$

4 FOAMAT( WHAT IS YOUR ALPHA LEVE (ENTEH O TO STUP)? 1,

READ(5,

IF $(A, E 0,0,0) s T 0$

White $(6,1)$

WaIte $(6,1)$

FOAMATI $I$ DO YOU HISH TO CUARECT FOR RESTRICTED RANGE? $1 /$

$1,(X$ OH $N) ?(, B)$

exad $(5,6)$ a ins

romat (ai)

IF(ANS.EQ, ' N ' ) COTO

WHITE $(0,7)$

7 TOMAT (i ENTER THE POPULATION STANDARD DE VIATION 1,

AEA $D(5, \cdots)$ SDP

- PORMAT (" ENTE

$\operatorname{meA}(5, *) 8 D$

WRITE $(6,1)$

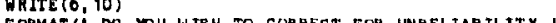

10 FORMAT(" DO YOU W

I (Y of $N)$ ? '

$\operatorname{READ}(5.6)$ AIS

IF (ANS. EO. ' $N$ ') GOTO 13

WhITE $(6,11)$

1 FCRMAT (' EHTER THE CR TTER ION RELIAGILITY 1,

READ(5,*) RC

12 FORMAT(' ENTER THE PREDICTOR RELIABILITY ',

$\operatorname{READ}(5, \cdots)$

WRITE $(6,1)$

4 FORMAT ( 1 YOU MAY COMPUTE EITHER 1=POHER, 2=SAMPLE SIZE, ',

1 - OR 3 =THE detectable conRElation. O=NEW PROBlem. '

' ( ЕNTEK 0, 1, 2, 3. ) '.1)

READ(5,") KK

IF (KK, LE. O. CR, KK. GT. 3) GOTO 3

GOTO $(15,22,28), \mathrm{KK}$

CALCULATE POWER

15 WRITE $(6,1)$

WRITE $(6,16)$

16 FORMAT (' ENTER YOUR UNCORRECTED CORRELATION ',s)

READ $(5, *)$ RT

$R C T=C R T(R T, S D P, S D S, R C, K P, R C R)$

IF(RT, EO. FCT) GOTO 19

WRITE $(6,17) R C R$

17 FORMAT( THE CORRELATION ADJUSTIMG FOR RANGE $=, 88.5)$

WRITE $(6,18)$ RCT

18 FORMATC THE CORRELTION ADJUSTING ALSO FOR UNRELIABILITY = '

1 , F 8.5)

WRITE $(6,1)$

WRITE $(6,20)$

20 FORMAT" WHAT IS YOUR SAMPLE SIZE? 1

1 (EMTER O TO CALCLATE AMOTHER ASPECT OF POWER) , 3)

READ $(5, *) \quad X N$

IF (XM,EO. O. O) GOTO

PR =POWR (RCT, XN, A)

21 FOHAAT $(1 /$, YOUR POWER IS $1, F 12,6 / 1)$

GOTO

CALCULATE SAMPLE SIZE

22 WRITE $(6,1)$

WRITE $(6,16$ )

READ $(5, *)$ RT

$R C T=C R T$ (RT, SDP, SDS, RC, RP, ACR

IF(RT.EO, RCT) GOTO 23

WRITE $(6,17)$ RCR

WRITE $(6,18)$ RCT

23 WRITE $(6,1)$

24 FORMAT ( 1 ENTER DESIRED POWER ( 0 ( POWER \& 1 ) 1,

1 ' ENTER 1 TO BEGIN a NEW PROBLEM',

2 ' ENTER O TO COMPUTE NEW ASPECT OF POWER ',

READ(5,") PR

IF (PR. LE. 0. 0) GOTO 13

IF (PR, CE, 1, O) GOTO 3

$Z R=F Z(R C T)$

$Z A=C V(A / 2,0)$

$2 A=C V$
$Z P=C$$(\mathrm{PR})$

$X N=((2 A-2 P) / 2 R) \cdots+2+3.0$

$X N=I N T(X H+.5)$

IF $(X N, G T, 5000.0)$ GOTO 26

IF (XN,LT, 2, D)XH 52,0

PC SPOWR(RCT, XN, A)

WRITE $(6,25) X M, P C, P R$

25 FOAMAT(' SAMPLE SIZE OF',F6.0,1 GIVES A POWER OF', F8.5,

I'As cho

26 WRITE $(6,27)$

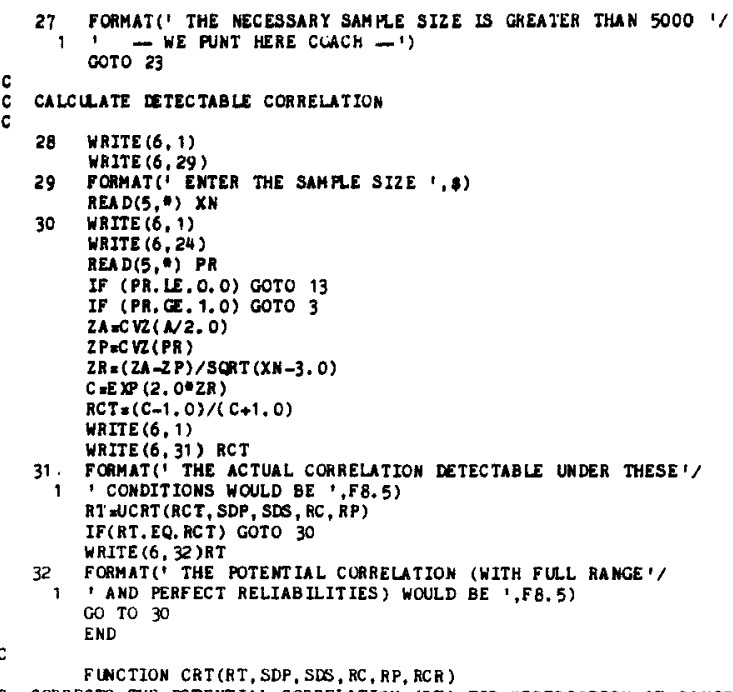

C CORRECTS THE POTENT, SDP CORRELATION, RCR ) FCR RESTRICTION OF RANGE C (SDP=POP, S D SDS SAMPLE S, D) RELIAB IIITY; R P =PREDICTOR RELIAB ILITY) CRT $=\mathrm{RT}$

IF (RC"R PAS DS "S DP. LE. 0. 0) RETUR

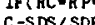

$C=S D S / S D P$

$C R T=C * R C R / S O A T(C * C * B C R * R C R-R C R * B C R+1.0)$

RETUR N

RETUR
END

C FUNCTION UCRT (RCT, SDP, SDS, RC, RP)

C CALCULATES POTENTTAL CORRELTTON FRCM ACTUAL CCRRELATION (RCT)

ADJUST ING FOH RA HGE RESTR ICTION AND UNRELIAL TITY TCRT FOH

IF (RCAR PASDS $\triangle S D P, L E, O, 0)$ RETURN

$C=S D S / S D P$
$R C R=R C T / S O F T(R C T * R C T+C * C *(1,0-R C T * H C T)$

UCRT $=$ RCR / SORT $(R C * R P)$

RETUR N

END

C COMPUTE THE POWER OF THE F TEST FOA R, WITH SAMPLE SIZE, XW,

C AND ALPHA, $A$.

$2 R+F Z(R)$

$2 A=C \mathrm{Z}(N / 2.0)$

2P=ZA-2A=SORT $(X N-3.0)$

$P O W R=Z P R B\langle 2 P\}$

RETUR:

FUCTION FZ(A)

RAMSFCRMATION

$F 2$ - $0.5 * a \log ((1,+1) /(1,-A))$

RETUR

TLNCTION 2 PHB (2)

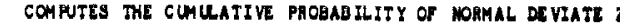

C (INTECRAL OP THE NORMAL DISTRIBUT ION FRCM TME INITY TO 2 )

$x \rightarrow 48$ ( 2$)$

2 PR8 0 .

$\operatorname{IF}(x . \sigma \pi, 12.) \operatorname{coto} 2$

Q.. $39894228 \omega \mathrm{EP}(-\mathrm{x}+\mathrm{x} / 2$.

$\operatorname{Ir}(x .67 .3 .7)$ 10 TO

$I=9 . /(1 .+23164194 x)$

P.. 31938153 ตT

PAP $=358563782$ ar ond

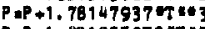

$P=P-1,821255978-T$ W

$P=P+1.330274429 * T * 5$

$2 P A B=Q$ QP

CO TO 2

2 PRB 0 ( $(\operatorname{sont}(4,+x-x)-x) / 2$

IF (2. LT, 0.) 2PRB =1, $Z$ PRB

RETUR

FUNCTION CVZ( $M$ )

THE MORMAL CURVE FOR A ONE-TAILED

EOAL TO $A$.

$A=A A$

IF (A.LT. . 5)Goto 1

$A=1,-4$

$S N=1$.

IF ( A, LT , T, E-34)STOP 

$72-.5$
$F_{k=0}=5$
0.5
PL $2=2$ PRB $(-.5)$
$P L 2=A L O G(P L 2)$
$P E=Z P R B(-5)$
PL $X=A L O G(A)$

F $1=F 2$
F $2=F$

$K=K+1$

$P L 1=P L 2$

$P L 2=1000$.

IF (PE.GT. 0.)PL $2=A L O G(P E)$

$F=F 1+(P L X-P L 1) *(F 2-F 1) /(P L 2-P L 1)$

$P E=2$ PRB ( $F$ )

IF (ABS (PE/A-1.). .GT . . 000001) GOTO 2

$C V Z S N=$

END

(Revision accepted for publication May 24, 1985.) 